\title{
Association Between Bone-lead Concentration and Aggression in Youth From a Sub-cohort of the Birth to Twenty Cohort
}

Nonhlanhla Tlotleng ( $\nabla$ nonhlanhlat@nioh.ac.za )

National Health Laboratory Service https://orcid.org/0000-0003-1526-2495

Nisha Naicker

University of Johannesburg - East Rand Campus: University of Johannesburg

Angela Mathee

South African Medical Research Council

Andrew C. Todd

Icahn School of Medicine at Mount Sinai

Palesa Nkomo

University of the Witwatersrand Faculty of Health Sciences

Shane A Norris

University of the Witwatersrand

Research

Keywords: Bone lead, blood lead, aggression, BT20 Cohort, KXRF, late adolescence, South Africa

Posted Date: August 26th, 2021

DOl: https://doi.org/10.21203/rs.3.rs-832446/v1

License: (1) This work is licensed under a Creative Commons Attribution 4.0 International License.

Read Full License 


\section{Abstract}

Background: An association between blood-lead levels and aggression has been demonstrated in children and adolescent youth in South Africa. However, there are limited studies that have assessed aggression as an outcome for cumulative lead exposure using bone-lead concentration. The aim of this study was to assess the association between bone-lead concentration and aggressive behaviour among a sample of the youth in South Africa.

Methods: Bone lead in 100 participants (53 males and 47 females) recruited and followed in the Birth to Twenty (BT20) Cohort were measured using ${ }^{109} \mathrm{Cd}$-based, K-Shell X-ray Fluorescence (KXRF). The BussPerry Aggression questionnaire was used to measure aggressive behaviour. Linear regression models were fitted to determine the association between aggression score for physical, verbal, anger and hostility and bone lead, adjusting for known confounders.

Results: The study participants were between the ages of 23 and 24 years. A one-microgram-per-gram increase in bone lead was found to increase the score for all four scales of aggression, but significantly only for anger ( $\beta=0.2$ [95\% $\mathrm{Cl} 0.04-0.370]$ ). Psychosocial factors such as a history of family violence and exposure to neighbourhood crime were found to be significant predictors for aggression.

Conclusion: The study provides a preliminary overview of the relationship between cumulative lead exposure and behavioural problems such as aggression. A larger sample, across exposed communities, may prove more definitive in deciding whether further investigating this association could maximize generalizability. Such information could be crucial in the drafting of policies designed to combat crime associated with youth aggression in South Africa.

\section{Introduction}

Lead exposure has been found to increase the risk of aggressive behavior later in life (1). Children who have been exposed to lead have been found to present elevated risk of delinquent behavior during adulthood and later adulthood (2). At low exposure levels, lead may cause acute and long-term health effects, such as neurotoxicity, that can subsequently affect behaviour and compromise intellectual abilities (3). Environmental pollution, contaminated soil, dust, water and food, as well as painted children toys, are sources by which the public becomes exposed to lead (4). As an example, lead is released into the environment from deteriorating lead paint applied to walls, door frames and windows in houses, schools and other buildings.

The Port Pirie Cohort study in Australia was one of the first studies to evaluate the association of elevated blood-lead levels (BLLs) and "emotional and behaviour problems" in children (5). In the study, a significant association between behavioural problems, including aggressive behaviour and cumulative BLLs, was found in boys and girls ages eleven to thirteen years (5). In SA youth, elevated blood levels were significantly associated with aggressive behaviour in young boys (11-13 years), after adjusting for socioeconomic status (SES) factors (6-8). Similarly, Nkomo et al. (2018) reported an association 
between elevated BLLs in adolescents aged fourteen to fifteen years and direct forms of aggression, such as verbal and physical (7).

Studies have also investigated the association between bone-lead concentration, a measure of cumulative lead exposure, and behavioural problems, including aggressive behaviour: Needleman et al. (1996) reported a significant association between elevated bone-lead concentration and aggression in eleven-year-old American boys (1). In a subsequent study, Needleman et al. (2002) assessed the association between bone-lead levels and criminal behaviour in convicted delinquents, aged 12-18 years (3). In the study, bone-lead levels in detained, delinquent youth were reported to be higher (mean 11, SD \pm $33 \mathrm{ppm}$ ) than those in a control group (mean 1.5, SD $\pm 32 \mathrm{ppm}$ ) of delinquent high-school youths. The odds of delinquent behaviour were shown to be greater in youth with higher bone-lead levels compared to those with lower levels (3).

A study in 2009, conducted in South Africa by the Centre for Justice and Crime, identified some of the key factors that may heighten aggressive behaviour in both young males and females (9). These included psychosocial factors such as history of family violence, exposure to crime and violence, interaction with delinquent peers and substance abuse and the home environment situation $(9,10)$. It has been shown that children raised in households with single parents may show tendencies of aggressive behaviour compared to those who were raised in households with two parents $(10,11)$. In addition, exposure to lead can be exacerbated by social determinant factors, such as poverty, low level of education and poor living conditions $(3,12-14)$. While studies assessing lead exposure, aggressive behaviour and delinquency have mainly focused on children (age 14 to 15 years), this study assessed the association between bonelead levels and aggressive behaviour among males and females in early adulthood (age 23 to 24 years), followed within a cohort of children previously exposed to lead. Furthermore, our study uses structural equation modelling (SEM) to assess direct and indirect pathways in the relationship between bone-lead concentration and aggression. Identifying environmental risk factors that may increase aggressive behaviour among the youth may assist in determining preventable factors associated with aggression.

\section{Materials And Methods}

\section{Study setting/site}

The BT20 Cohort was established in South Africa (SA) in the 1988 with the aim of conducting a longitudinal study to assess the health of children in the Johannesburg area (15). The study enrolled women in their second and third trimester of pregnancy. Singleton children $(n=3273)$ who were residents of Soweto-Johannesburg and born between April and June 1990 were enrolled into the birth cohort and were followed from birth to date (16). The entry criterion included that mother and baby remain in the Soweto-Johannesburg area until the child was at least six months old. Attrition rate in the first two decades of the cohort has also been relatively low (30\%), with most occurring in infancy and early childhood. At the time of writing, there are just over 2,000 children and families participating in the study (17). 


\section{Study population}

A sub-cohort (approximately $n=500$ ) from the birth cohort study was formed at age 9 years to investigate the in-depth longitudinal changes in body composition and whole-body, lumbar spine and hip-bone mass during adolescence and into adulthood (Bone Health Cohort). The current study sample was comprised of young adult (23 and 24 years) males $(n=53)$ and females $(n=47)$ recruited from Bone Health Cohort in Johannesburg, South Africa.

\section{Study variables}

Bone-lead concentration was the exposure variable in this study. Tibia-lead concentration was measured in the study participants using K-shell X-ray fluorescence (KXRF), a non-invasive procedure (18). Results from KXRF spectrometry with humans have been used for decades in dozens of studies as a biomarker to assess cumulative lead exposure levels (19). XRF uses ${ }^{109} \mathrm{Cd}$ as the source that emits $88.035 \mathrm{keV}$ photons to fluoresce $\mathrm{x}$-rays from the lead atoms stored in bone. The silver $\mathrm{x}$-rays that also accompany the decay of ${ }^{109} \mathrm{Cd}$ are filtered by copper, minimizing participant radiation dose (effective dose is equivalent to less than ten minutes of natural background radiation for an adult) (20). Backscattered photons and fluoresced $\mathrm{Pb}$ x-rays are recorded with a spectroscopy system (intrinsic germanium detector, preamplifier and digital signal processor). The spectrum (distribution of photons against energy) then undergoes nonlinear least-squares fitting to extract the areas of the lead $\mathrm{x}$-ray peaks seen atop the Compton scattering background. Coherent scatter normalization, matrix correction and comparison to calibration measurements, made of lead-doped plaster of Paris $\left(\mathrm{CaSO}_{4} \cdot 2 \mathrm{H}_{2} \mathrm{O}\right)$ calibration standards, yield in vivo concentrations in micrograms of lead per gram of bone mineral (21).

\section{Measurement of Aggression}

Aggression was the outcome variable in the study. The Buss-Perry Aggression Questionnaire (BPAQ) was administered to study participants to measure aggression as a score (22). The BPAQ is a validated tool that has been used in studies primarily in low-to middle-income countries $(23,24)$. The questionnaire consists of twenty-nine items that measure four components of aggression: physical and verbal aggression, hostility and anger. Physical aggression consisted of nine questions, and the scoring from this item ranged from 18 to 38 . Verbal aggression had five items, with the scoring ranging from 10 to 25 . Anger consisted of seven items, with a scoring range of 14 to 35 ; and hostility consisted of eight items, with a scoring range of 10 to 37 (22). The level of aggression in the questionnaire was rated on a fivepoint Likert scale, presented as 1 (extremely uncharacteristic of me), 2 (somewhat uncharacteristic of $\mathrm{me}$ ), 3 (neither uncharacteristic nor characteristic of me), 4 (somewhat characteristic of me) and 5 (extremely characteristic of me). The total aggression scores of the twenty-nine items were also calculated, and these were also used in the analyses. A Cronbach's a reliability coefficient was used to determine the reliability of the items. An alpha coefficient of 0.72 was obtained for the nine items of physical aggression, 0.6684 for the seven items of anger, 0.7150 for the eight items of hostility and 
0.5640 for the five items of verbal aggression, indicating acceptable reliability among the items. The 29 items reported a scale reliability coefficient of 0.8364 , similar to that reported previously (24).

\section{Study confounders}

A separate questionnaire was administered to the study participants to obtain information on demographics, socio-economic and psychosocial factors. A confounding variable in the study was defined as a variable that is a risk factor for aggression or is associated with, but is not a consequence of, bone lead concentration. The following variables were therefore considered as study confounders and potential predictors of aggression: age; sex; level of schooling (categorized into three: Grade 5 or less, grade 6-12 and tertiary education); presence of both parents at home; home environment; neighbourhood crime; profile of illegal substance abuse (use of drugs such as dagga and glue); use of alcohol; and socioeconomic factors (maternal education, type of housing and occupation status). Information on the participant's home environment (referred to in this analysis as "history of family violence") was obtained by asking the participants to respond to the following statements: "We argue a lot in our family, "people in my family hardly ever lose their temper" and "people in my family sometimes hit each other when they are angry". Participant were required to agreed or responded with a "Yes" (coded as 1) or disagreed or responded with a "No" (coded as 2). To obtain information on neighbourhood factors, the participants were asked how they generally feel in their neighbourhood: a "feeling of somewhat unsafe or very unsafe" coded as 1 and "somewhat safe or very safe" coded as 2. Questions on whether the participants had personally experienced crime and violence in the neighbourhood were asked: "ever in your life experienced any crime", with "Yes" coded as 1 and "No" coded as 2. Socioeconomic status was measured by considering three levels: (1) maternal level of education (categorized into four levels: no formal education, primary schooling, secondary schooling and post-school education); (2) type of housing: formal (such as free-standing house, townhouse or hostel) and informal (shack, squat and any other informal room); and (3) participant's level of education and occupational status as proxies.

\section{Ethical consideration}

Ethical approval was obtained for this study from the University of the Witwatersrand, Human Ethics Research Committee (M 191116).

\section{Statistical Analysis}

All data cleaning and analysis were performed using Stata version 15 (StataCorp. 2017; Stata Statistical Software: Release 15. College Station, TX: StataCorp LP). Data were checked for duplicates and missing values. Study participants' psychosocial and demographic characteristics were described. The categorical variables were presented as frequencies and proportions. Data were stratified by sex. The Pearson chi-squared test was used to assess the association between categorical variables. Continuous variables in the study were bone-lead concentration and the four aggression level scores (physical, verbal, anger and hostility). Tibia-lead concentrations were analysed in the study as a continuous variable to retain all values, including values below the detection limit and values lower than zero (22). The 
distribution of the continuous variables was checked for normality. Bone-lead concentrations were summarized as mean and SD, median, $25^{\text {th }}$ and $75^{\text {th }}$ Interquartile ranges (IQR), as appropriate. For continuous variables that were normally distributed, an independent Student's $t$-test was conducted to test for the difference in the mean. There was no further post hoc correction analysis required. Testing was set at the 0.05 level of significance. The geometric mean, median and ranges for the aggression scales were described, and a Student's t-test was conducted to test for the differences in means, stratified by sex.

To assess the association between bone-lead concentration and aggression, a linear regression model was fitted. In the univariate analysis, a simple linear regression was fitted, with each aggression scale as the outcome variable and with bone lead as the main explanatory variable. A backward elimination, using a liberal $p$-value of 0.20 , was used to include variables in the multivariate model. Variables with $p \leq 0.001$ were reported as highly significant, and those with $p \leq 0.08$, also retained in the final model, were reported as marginally significant. Age and sex were retained as study confounders in all multivariable models. Goodness of fit was assessed via regression diagnostics, and residuals were assessed to check the assumptions of linearity, normality and constant variance and the adequacy of the final models.

To further quantify and assess the direction of the relationship between bone lead levels and aggression, structural equation modelling (SEM) was performed. In the SEM model, aggression was the latent variable, which, as previously indicated, was assessed via four observed variables: physical aggression, verbal aggression, hostility and anger. All observed variables were denoted by rectangular boxes, and latent variables (unobserved) were denoted in ovals. In model I, pathways between educational level, age, sex, type of housing, occupational status and maternal education were created, as these variables were identified as determinants of bone-lead levels (25). Subsequently, the variables (educational level, age, sex, type of housing, occupational status and maternal education) created indirect pathways to aggression via (continuous) bone-lead concentration. Direct predictors for aggression in model II were: a history of family violence, exposure to crime, growing up with a single parent and use of drugs and alcohol. To assess model fit, SEM fit indices that included: the root mean square error (RMSE), standardized root mean square residual (SRMR), comparative fit index (CFI) and Tucker Lewis index (TLI). A RMSE below 0.05, P-close greater than 0.05, SRMR greater than 0.08, CFI and TLI value of 0.95 and above indicated a good fitting model (26). Where necessary, the model was checked for improvement using modification of indices.

\section{Results}

The results of the socio-demographic and psychosocial characteristics of the study sample stratified by sex are shown in Table 1. Overall, the sample consisted of 53 male and 47 female participants. Close to $60 \%$ of the study participants reported living with a single parent; $58.7 \%(n=27)$ of females and $62.3 \%(n$ $=33)$ of males. Most of the study participants had a secondary-level education: $60.4 \%(n=32)$ of the males and $61.7 \%(n=29)$ of the females; only a few $(10 \%)$ had tertiary/post-school education. For 
maternal education, a large proportion of participants (78\%) reported their mothers to have had secondary-level education.

Only $3 \%$ of the study participants reported living in informal dwelling such as a shack. Approximately half the participants were employed on a casual/part-time basis or self-employed (52\%). Experiences in the home environment were obtained by asking whether the participants had "ever" experienced violence or aggressive behaviour in the family, and most (67\%) disagreed with the statement. In addition, many of the participants reported a feeling of being unsafe or somewhat unsafe in their neighbourhood: $84.9 \%$ (n $=45)$ of males and $74.5 \%(n=35)$ of the females. Previous use of alcohol and drugs was more common among males than in females, with $100 \%$ of males $(n=53)$ reporting having used alcohol and $75.5 \%(n=$ 40) of males illicit drugs such as hallucinogens, cannabis, cocaine, inhalants and opiates, among others. A chi-square test showed the use of drugs and alcohol to be significantly different between males and females $(p<0.001)$. 
Table 1

Description of Socio-Demographic and Psychosocial Characteristics of Study Participants Stratified by Sex

\begin{tabular}{|c|c|c|c|}
\hline Variable & $\begin{array}{l}\text { Males }(n, \%)(n= \\
53)\end{array}$ & $\begin{array}{l}\text { Females }(n, \%)(n \\
=47)\end{array}$ & $\begin{array}{l}\text { Total }(\mathrm{N}= \\
\text { 100) }\end{array}$ \\
\hline \multicolumn{4}{|l|}{ Socio-Demographic Factors } \\
\hline \multicolumn{4}{|c|}{ Living with Both Parents (missing $n=1$ ) } \\
\hline Yes & $20(37.7)$ & $19(41.3)$ & $39(39.4)$ \\
\hline No & $33(62.3)$ & $27(58.7)$ & $60(60.6)$ \\
\hline \multicolumn{4}{|l|}{ Level of Education } \\
\hline Grade 5 or less & $14(26.4)$ & $8(17.0)$ & $22(22.0)$ \\
\hline Grade 6-12 & $32(60.4)$ & $29(61.7)$ & $61(61.0)$ \\
\hline Tertiary & $7(13.2)$ & $10(21.3)$ & $17(17.0)$ \\
\hline \multicolumn{4}{|l|}{ Maternal Education } \\
\hline No formal education & 0 & $1(2.1)$ & $1(1.0)$ \\
\hline Primary & $5(9.4)$ & $6(12.8)$ & $11(11.0)$ \\
\hline Secondary & $42(79.3)$ & $36(76.6)$ & $78(78.0)$ \\
\hline Post-school training & $6(11.3)$ & $4(8.5)$ & $10(10.0)$ \\
\hline \multicolumn{4}{|l|}{ Socio-Economic Factors } \\
\hline \multicolumn{4}{|l|}{ Type of Housing } \\
\hline $\begin{array}{l}\text { Formal housing (RDP/hostel/free } \\
\text { standing) }\end{array}$ & $51(96.2)$ & $46(97.9)$ & $97(97.0)$ \\
\hline Informal (shack) & $2(3.8)$ & $1(2.1)$ & $3(3.0)$ \\
\hline \multicolumn{4}{|l|}{ Occupation } \\
\hline Employed, full time & $19(35.9)$ & $18(38.3)$ & $37(37.0)$ \\
\hline Casual/part-time/self-employed & $28(52.8)$ & $24(51.1)$ & $52(52.0)$ \\
\hline Never been employed & $6(11.3)$ & $5(10.6)$ & $11(11.0)$ \\
\hline \multicolumn{4}{|l|}{ Home and Neighbourhood } \\
\hline \multicolumn{4}{|l|}{ Exposure to family violence } \\
\hline Yes & $19(35.9)$ & $14(29.8)$ & $33(33.0)$ \\
\hline No & $34(64.1)$ & $33(70.2)$ & $67(67.0)$ \\
\hline
\end{tabular}




\begin{tabular}{|c|c|c|c|}
\hline Variable & $\begin{array}{l}\text { Males }(n, \%)(n= \\
53)\end{array}$ & $\begin{array}{l}\text { Females }(n, \%)(n \\
=47)\end{array}$ & $\begin{array}{l}\text { Total }(\mathrm{N}= \\
100)\end{array}$ \\
\hline \multicolumn{4}{|l|}{ Attitude toward Neighbourhood } \\
\hline somewhat unsafe/very unsafe & $45(84.9)$ & $35(74.5)$ & $80(80.0)$ \\
\hline Somewhat safe/very safe & $8(15.1)$ & $12(25.5)$ & $20(20.0)$ \\
\hline \multicolumn{4}{|l|}{$\begin{array}{l}\text { Exposure to Crime and Violence in } \\
\text { Neighbourhood }\end{array}$} \\
\hline Yes & $25(47.2)$ & $19(40.4)$ & $44(44.0)$ \\
\hline No & $28(52.8)$ & $28(59.6)$ & $56(56.0)$ \\
\hline \multicolumn{4}{|l|}{ Substance Abuse } \\
\hline \multicolumn{4}{|l|}{ Drugs } \\
\hline Yes & $40(75.5)$ & $6(12.8)$ & $54(54.0)$ \\
\hline No & $13(24.5)$ & $41(87.2)$ & $46(46.0)$ \\
\hline \multicolumn{4}{|l|}{ Alcohol } \\
\hline Yes & $53(100)$ & $42(89.4)$ & $95(95.0)$ \\
\hline No & 0 & $5(10.6)$ & $5(5.0)$ \\
\hline
\end{tabular}

The concentration of bone lead in males and females is summarized in Table 2. Female concentrations were marginally greater than those of males, but this difference was not statistically significant. The range was $5-11 \mu \mathrm{g} / \mathrm{g}$ bone mineral in males and $4-14 \mu \mathrm{g} / \mathrm{g}$ in females.

Table 2

Bone-Lead Concentrations

\begin{tabular}{|lllll|}
\hline $\begin{array}{l}\text { Continuous Bone Lead Levels } \\
(\boldsymbol{\mu} \mathbf{g} / \mathbf{g} \text { bone mineral) }\end{array}$ & Males $(\mathbf{n = 5 3 )}$ & Females $(\mathrm{n}=\mathbf{4 7})$ & Total $\mathbf{N = 1 0 0}$ & P value* \\
\hline Mean (SD) & $8.1(4.4)$ & $9.4(6.1)$ & $8.7(5.3)$ & 0.2021 \\
\hline Range & & & & \\
\hline Minimum & 0 & 0 & 0 & \\
\hline Median (IQR) & $8(5-11)$ & $10(4-14)$ & $9(5-12.5)$ & \\
\hline Maximum & 18 & 21 & 21 & \\
\hline
\end{tabular}

The geometric mean, median and ranges of the four scales of aggression, stratified by sex, are shown in Table 3; as stated above, higher scores indicate more aggressive behaviour. Males reported an insignificantly greater mean score for physical aggression (27.2 and a geometric mean of 26.7), even 
though the ranges for females were higher $(18-4)$. Females scored insignificantly greater for anger, hostility and verbal aggression. The total score for aggression was also insignificantly greater in females (93.8) than in males (91.8).

Table 3

Geometric Mean, Median and Range of Aggression Scores by Sex

\begin{tabular}{|c|c|c|c|c|c|c|c|}
\hline \multirow[b]{2}{*}{$\begin{array}{l}\text { Aggression } \\
\text { Scale }\end{array}$} & \multicolumn{3}{|c|}{ Males $(n=53)$} & \multicolumn{3}{|c|}{ Females $(n=47)$} & \multirow{2}{*}{$\begin{array}{l}\mathrm{p} \\
\text { value }\end{array}$} \\
\hline & $\begin{array}{l}\text { Geometric } \\
\text { mean }\end{array}$ & $\begin{array}{l}\text { Mean } \\
\text { (SD) }\end{array}$ & Range & $\begin{array}{l}\text { Geometric } \\
\text { mean }\end{array}$ & $\begin{array}{l}\text { Mean } \\
\text { (SD) }\end{array}$ & Range & \\
\hline $\begin{array}{l}\text { Physical } \\
\text { aggression }\end{array}$ & 26.7 & $\begin{array}{l}27.2 \\
(4.7)\end{array}$ & $\begin{array}{l}18- \\
36\end{array}$ & 26.0 & $\begin{array}{l}26.5 \\
(5.1)\end{array}$ & $\begin{array}{l}18- \\
38\end{array}$ & 0.4782 \\
\hline Anger & 20.5 & $\begin{array}{l}20.9 \\
(4.4)\end{array}$ & $\begin{array}{l}14- \\
32\end{array}$ & 21.7 & $\begin{array}{l}22.3 \\
(5.3)\end{array}$ & $\begin{array}{l}14- \\
35\end{array}$ & 0.1615 \\
\hline Hostility & 24.9 & $\begin{array}{l}25.7 \\
(6.2)\end{array}$ & $\begin{array}{l}10- \\
38\end{array}$ & 25.8 & $\begin{array}{l}26.5 \\
(5.9)\end{array}$ & $\begin{array}{l}14- \\
37\end{array}$ & 0.5193 \\
\hline $\begin{array}{l}\text { Verbal } \\
\text { aggression }\end{array}$ & 17.0 & $\begin{array}{l}17.4 \\
(3.8)\end{array}$ & $\begin{array}{l}10- \\
25\end{array}$ & 18.2 & $\begin{array}{l}18.6 \\
(3.7)\end{array}$ & $\begin{array}{l}10- \\
25\end{array}$ & 0.1180 \\
\hline Total score & 90.0 & $\begin{array}{l}91.2 \\
(14.3)\end{array}$ & $\begin{array}{l}57- \\
118\end{array}$ & 92.6 & $\begin{array}{l}93.8 \\
(15.4)\end{array}$ & $\begin{array}{l}66- \\
127\end{array}$ & 0.3768 \\
\hline
\end{tabular}

\section{*Student t-test used to obtain p value}

Bone-lead concentration was found not to be significantly associated with physical aggression, verbal aggression and hostility (see supplementary tables), but was significantly associated with anger.

Tables 4 and 5 show the univariate and multivariable analysis of mean aggression score for anger and bone-lead concentration, as well as anger and other study predictors. Factors such as maternal education, being exposed to family violence and a feeling of being unsafe in the neighbourhood were significantly associated with anger in the unadjusted model. 
Table 4

Unadjusted Univariate Model Showing the Association Between Bone-Lead Concentration and Anger Aggression.

\begin{tabular}{|c|c|c|c|c|}
\hline Factors & Mean & $P$ value & $95 \% \mathrm{Cl}$ & \\
\hline $\mathrm{Pb}$ & 0.1 & 0.246 & -0.076 & 0.292 \\
\hline \multicolumn{5}{|l|}{ Age } \\
\hline$=23$ years & ref & & & \\
\hline$=24$ years & -0.3 & 0.822 & -2.572 & 2.047 \\
\hline \multicolumn{5}{|l|}{ Sex } \\
\hline Male & ref & & & \\
\hline Female & 1.4 & 0.162 & -0.558 & 3.299 \\
\hline \multicolumn{5}{|c|}{ Grew up with Both Parents } \\
\hline Yes & ref & & & \\
\hline No & -0.4 & 0.701 & -2.304 & 1.555 \\
\hline \multicolumn{5}{|l|}{ Education Level } \\
\hline Grade 5 or less & 2.3 & 0.157 & -0.875 & 5.329 \\
\hline Grade 6-12 & 0.1 & 0.941 & -2.537 & 2.733 \\
\hline Tertiary & ref & & & \\
\hline \multicolumn{5}{|l|}{ Maternal Education } \\
\hline No formal education & 9.8 & $0.047 * *$ & 0.147 & 19.366 \\
\hline Primary & 2.0 & 0.193 & -1.046 & 5.104 \\
\hline Secondary & ref & & & \\
\hline Post school training & -0.1 & 0.929 & -3.351 & 3.063 \\
\hline \multicolumn{5}{|l|}{ Type of Housing } \\
\hline Formal & ref & & & \\
\hline Informal & 1.8 & 0.523 & -3.850 & 7.527 \\
\hline \multicolumn{5}{|l|}{ Occupation } \\
\hline Employed & ref & & & \\
\hline Casual & 1.8 & 0.084 & -0.249 & 3.891 \\
\hline Unemployed & 1.1 & 0.526 & -2.246 & 4.364 \\
\hline
\end{tabular}




\begin{tabular}{|lllll|}
\hline Factors & Mean & P value & $95 \%$ Cl & \\
\hline Exposure to Family Violence & & & & \\
Yes & 4.3 & $<0.001^{\star \star \star}$ & 2.459 & 6.212 \\
\hline No & ref & & & \\
Attitude toward Neighbourhood & & & & \\
somewhat unsafe/very unsafe & -2.6 & $0.031^{\star \star}$ & -4.998 & -0.252 \\
\hline Somewhat safe/very safe & ref & & & \\
\hline Exposure to Crime and Violence(Neighbourhood) & & & & \\
\hline Yes & -0.9 & 0.362 & -2.851 & 1.049 \\
\hline No & ref & & & \\
\hline Drug use & & & & \\
\hline Yes & 0.4 & 0.674 & -1.535 & 2.364 \\
\hline No & ref & & & \\
\hline Alcohol use & & & & \\
\hline Yes & -0.2 & 0.944 & -4.620 & 4.303 \\
\hline No & ref & & & \\
\hline
\end{tabular}

\section{*** $p<0.001$ highly significant; ${ }^{\star *} \mathrm{p}<0.05$ significant}

In Table 5, the final model shows that previous exposure to family violence, "feeling somewhat unsafe/very unsafe toward neighbourhood" and being exposed to neighbourhood crime and violence were significantly associated with mean aggression score for anger. Adjusting for confounding variables, the final model shows that a one-microgram-per-gram increase in bone lead significantly increases the mean aggressive score for anger by 0.25 [95\% Cl: 0.04-0.37]. This increase was similar for physical aggression (coefficient $=0.093$ [95\% Cl: $-0.01-0.27$ ]); verbal aggression (coefficient $=0.093$ [95\% Cl: $-0.05-$ $0.23]$ and hostility (coefficient $=0.030[95 \% \mathrm{Cl}-0.19-0.26]$ ) (see supplementary tables). 
Table 5

Multivariable model of the Association between Anger and Bone Lead, after adjusting for Study Confounders

\begin{tabular}{|lllll|}
\hline Factors & Mean & P value & $95 \% \mathrm{Cl}$ & \\
\hline $\mathrm{Pb}$ & 0.2 & $0.017^{\star \star}$ & 0.038 & 0.370 \\
\hline Age & & & & \\
= 23 years & ref & & & \\
= 24 years & -0.6 & 0.593 & -2.632 & 1.512 \\
\hline Sex & & & & \\
\hline Male & ref & & & \\
\hline Female & 1.0 & 0.231 & -0.676 & 2.765 \\
\hline Exposure to family violence & & & & \\
\hline Yes & 4.8 & $<0.001^{\star * \star}$ & 2.982 & 6.691 \\
\hline No & ref & & & \\
\hline Attitude toward neighbourhood & & & & \\
\hline somewhat unsafe/very unsafe & -2.3 & $0.041^{\star *}$ & -4.461 & -0.089 \\
\hline Somewhat safe/very safe & ref & & & \\
\hline Exposure to crime and violence & & & & \\
(neighbourhood) & & & & \\
\hline Yes & -1.6 & $0.068^{*}$ & -3.383 & 0.125 \\
\hline No & ref & & & \\
\hline
\end{tabular}

Figure 1 shows the structural equation model with direct and indirect pathways between PB and aggression and between PB and variables considered to be determinants of lead levels. The indirect pathways to aggression show the effect of socioeconomic status predictors (education, maternal education, and employment status) and demographics (age, sex) on PB (light khaki arrows). Consistent with the linear regression analysis (Supplementary-Table 4), a positive path coefficient between PB and aggression (0.082) was obtained in a direct pathway (red arrow), but this pathway was not statistically significant $(p=0.183)$ (pathways to other predictors of aggression are shown in light brown). The pathway from maternal education to PB was found to be significant $(p<0.001)$. The path coefficients between age, maternal education and PB showed negative coefficients. The pathway between history of family violence and aggression was found to be significantly associated with aggression $(p<0.001)$.

\section{Discussion}


This study investigated the association between bone lead levels and aggressive behaviour among lateadolescent youth, aged 23 and 24 years. Lead exposure has been reported to cause adverse health effects in minority groups, including changes in behavior. In this study, the mean bone lead concentration was 8.1 (SD 4.4) $\mu \mathrm{g} / \mathrm{g}$ in males and $9.4(6.1) \mu \mathrm{g} / \mathrm{g}$ in females. Sex has been shown to be an important determinant of bone lead levels $(27,28)$. Our results showed that the mean concentration of bone lead was slightly higher in females compared to males, even though the difference was not statistically significant, consistent with Roy et al.1997.

The description of the psychosocial, demographic and socioeconomic characteristics, stratified by sex, showed that the majority of the participants in the study did not grow up with both their parents $(60.6 \%)$ and that most reported living in formal housing (97\%). As reported in the literature, children who grow up in households with single parents were found to display more aggressive behaviour compared to those who grew up with both parents (11). Other sociodemographic factors, including low income, education status and dwelling in older housing, have been attributed to higher bone lead levels in children (29). These factors, though found in this study not to be significant in the final model between bone lead concentration and anger, have been reported as risk factors for aggressive behaviour in lead-exposed children $(6,11)$.

The analysis showed that use of substances such as drugs and alcohol was more prevalent in males than in females. In a multivariable model, alcohol and drug use were found not to be significant predictors of aggression. Varying trends in sex difference in alcohol and certain illicit drug use, such as heroin and hallucinogens, have been seen: although in early and mid-adolescent years, substance use in females matches that of males, in late adolescence the prevalence of substance use tends to become greater in males than in females $(10,30)$. The mean score for physical aggression among the males in this study was slightly higher than the mean score for females, reflecting findings from similar studies: irrespective of age $(8,31)$, males reported more direct forms of aggression, such as physical aggression, than females, whereas females reported indirect forms of aggression such as hostility and anger (32). A small sex difference has previously been detected for hostility (22).

After adjusting for study confounders, we found a significant association between bone-lead levels and anger aggression. In addition, the model showed a positive coefficient indicating that an increase in bone lead concentration increases the aggression score for anger. Reports on the psychological impact of anger show that anger affects the brain by compromising the neurons in the hypothalamus where the stress response occurs (33). In the literature, the adverse effect of lead on brain function has been demonstrated; thus, accumulation of lead in the body may activate or trigger feelings of anger in individuals. Nonetheless, more detailed explanations of biological mechanisms are needed. Furthermore, it has been shown that individuals who exhibit anger usually have other aggressive behaviours such as hostility (33). Even though bone-lead levels were not associated with physical aggression, hostility and verbal aggression, anger may be the principal way of expressing aggression and, hence, the strong association in lead-exposed individuals. The adjusted analysis between bone-lead levels and anger in this study showed that a history of family violence and unsafe neighbourhoods were also associated with 
anger aggression. Children who grow up in a home environment where there is shouting and violence will tend to be angry at their situation (33).

Lower education levels, including those for maternal education status, are indirect measures of poor socioeconomic status and have been reported to be strongly associated with higher lead levels (34). SEM analysis showed a significant negative path coefficient between higher maternal education and bone-lead concentration, indicating that participants whose maternal parent has attained a higher education level would report lower levels in bone lead. Nonetheless, in a direct pathway between maternal education and aggression, we found no association, where higher education levels of the mothers indicated a decrease in aggressive behavior. In other studies, lower parental education has been associated with aggressive behaviour in children (35).

Disadvantaged communities in poor-resourced countries have been shown to be at a higher risk for environmental lead exposures (36). The primary sources of lead exposure for these communities are environmental pollution from houses previously painted with lead. In this study, the pathway between type of housing and bone-lead levels showed a non-significant association. Considering that the BT20 Plus Cohort is a community study conducted in the south-western township of Johannesburg where the homes are estimated at over 50 years old, it was expected that formal housing likely decorated with leaded paint would show a strong association with bone lead levels.

\section{Study Strength And Limitations}

One of the strengths of this study is the use of a non-invasive, authoritative and sensitive measurement procedure was used to quantify bone-lead levels in the cohort. Research that has used KXRF for repeated measurements of bone-lead levels has shown that the instrument provides credible precision of values compared to chemical analyses. Secondly, a reliable and validated tool was employed to quantify aggression scores in the study. Nonetheless, this study may present a limitation in terms of the sample size, making the results not generalizable to the population. Other limitations include the potential for bias, such as recall bias where participants may tend to underreport their aggressive behaviour patterns.

Information on other factors, such as occupational history related to lead exposure, smoking history, housing age or duration of residence at the current house of participants, as well as physical appearance of the homes in terms of peeling paint, were not collected. These factors could have improved the variance in the model explaining the relationship between bone-lead levels and anger aggression. In addition, other risk factors for aggression were not included in the psychosocial questionnaire, such as paternal history and food insecurity. Research has linked poor nutrition, more common in poorer communities, and low-income brackets with an increase in the body's lead absorption (37).

\section{Conclusion}


In summary, this study showed that a unit increase in cumulative lead exposure increased the mean score of aggression in late adolescents. Bone-lead concentrations were significantly associated with the aggression score for anger. This effect might pose adverse effects later in life that include violent behaviour (38) and participation in criminal activities (39). Further longitudinal studies employing a larger sample size in South African youth are needed to investigate more fully the relationship of these two important public-health factors.

\section{Declarations}

\section{Ethics approval and consent to participate}

I confirm that all relevant ethical guidelines have been followed, and any necessary Institutional research body (IRB) and ethics committee approvals for the study have been obtained. The Human Research Ethics Committee (Medical) of the University of the Witwatersrand (Ethics reference no: M191116). All methods were carried out in accordance with the accepted national and international guidelines and standards. Also, informed consent was obtained from all the participants.

\section{Consent for publication}

\section{NOT APPLICABLE}

\section{Availability of data and materials}

The datasets generated and/or analysed during the current study are SAMRC Development Pathways for Health Research Unit (DPHRU), University of the Witwatersrand, Johannesburg, South Africa. The data may be made available on request.

\section{Competing interests}

The authors declare that they have no competing interests.

\section{Funding statement}

The BT20 cohort, and Bone Health cohort, was funded by the Wellcome Trust (United Kingdom) and the Medical Research Council (South Africa), with support from the University of the Witwatersrand. No additional funding was obtained towards the completion of this analysis and the development of this manuscript.

\section{Authors contributions}

NT: Conceptualization, Formal Statistical Analysis and Writing-Original draft preparation. NN: Conceptualization, Supervision, Writing- Reviewing and Editing. AM: Conceptualization, and WritingReviewing and editing.: ACT: Methodology, Writing-Reviewing and Editing.: PN: Writing-Reviewing and Editing.: SAN: Conceptualization, Writing-Reviewing and Editing. 


\section{Acknowledgements}

The authors wish the acknowledge Medical Research Council (South Africa) and the DSI-NRF Centre of Excellence for Human Development at the University of the Witwatersrand, Johannesburg, South Africa. The authors also wish to thank the Birth to Twenty cohort study participants and their parents for their contribution in the study.

\section{References}

1. Needleman HL, Riess JA, Tobin MJ, Biesecker GE, Greenhouse JB. Bone lead levels and delinquent behavior. Jama. 1996;275(5):363-9. doi:10.1001/jama.1996.03530290033034.

2. Wright JP, Dietrich KN, Ris MD, Hornung RW, Wessel SD, Lanphear BP, et al. Association of prenatal and childhood blood lead concentrations with criminal arrests in early adulthood. PLoS Med. 2008;5(5):e101.

3. doi.org/10.1371/journal.pmed.0050101.

4. Needleman HL, McFarland C, Ness RB, Fienberg SE, Tobin MJ. Bone lead levels in adjudicated delinquents: a case control study. Neurotoxicol Teratol. 2002;24(6):711-7. doi.org/10.1016/S08920362(02)00269-6.

5. Njati SY, Maguta MM. Lead-based paints and children's PVC toys are potential sources of domestic lead poisoning-A review. Environmental pollution. 2019. doi.org/10.1016/j.envpol.2019.03.062.

6. Burns JM, Baghurst PA, Sawyer MG, McMichael AJ, Tong S-I. Lifetime low-level exposure to environmental lead and children's emotional and behavioral development at ages 11-13 years: The Port Pirie Cohort Study. Am J Epidemiol. 1999;149(8):740-9. doi.org/10.1093/oxfordjournals.aje.a009883.

7. Naicker N, Richter L, Mathee A, Becker P, Norris SA. Environmental lead exposure and sociobehavioural adjustment in the early teens: the birth to twenty cohort. Sci Total Environ. 2012;414:120-5. doi.org/10.1016/j.scitotenv.2011.11.013.

8. Nkomo P, Naicker N, Mathee A, Galpin J, Richter LM, Norris SA. The association between environmental lead exposure with aggressive behavior, and dimensionality of direct and indirect aggression during mid-adolescence: Birth to Twenty Plus cohort. Sci Total Environ. 2018;612:472-9. doi.org/10.1016/j.scitotenv.2017.08.138.

9. Nkomo P, Mathee A, Naicker N, Galpin J, Richter LM, Norris SA. The association between elevated blood lead levels and violent behavior during late adolescence: The South African Birth to Twenty Plus cohort. Environment international. 2017;109:136-45. doi.org/10.1016/j.envint.2017.09.004.

10. Leoschut $L$, Burton P. Building resilience to crime and violence in young South Africans: Centre for Justice and Crime Prevention; 2009. http://www.cjcp.org.za/uploads/2/7/8/4/27845461/research_bulletin_4__building_resiliency_to_crime_nyrs.pdf. Accessed 18 August 2021. 
11. Liu J, Lewis G, Evans L. Understanding aggressive behaviour across the lifespan. J Psychiatr Ment Health Nurs. 2013;20(2):156-68. doi.org/10.1111/j.1365-2850.2012.01902.x.

12. Usakli $\mathrm{H}$. Comparison of single and two parents children in terms of behavioral tendencies. International Journal of Humanities and Social Science. 2013;3(8):256 - 70. http://www.ijhssnet.com/journals/Vol_3_No_8_Special_Issue_April_2013/26.pdf. Accessed 18 August 2021.

13. Skerfving S, Löfmark L, Lundh T, Mikoczy Z, Strömberg U. Late effects of low blood lead concentrations in children on school performance and cognitive functions. Neurotoxicology. 2015;49:114-20. doi.org/10.1016/j.neuro.2015.05.009.

14. Gould E. Childhood lead poisoning: conservative estimates of the social and economic benefits of lead hazard control. Environmental health perspectives. 2009;117(7):1162-7. doi.org/10.1289/ehp.0800408.

15. Lin C, Kim R, Tsaih S-W, Sparrow D, Hu H. Determinants of bone and blood lead levels among minorities living in the Boston area. Environmental health perspectives. 2004;112(11):1147-51. doi.org/10.1289/ehp.6705.

16. Yach D, Cameron N, Padayachee N, Wagstaff L, Richter L, Fonn S. Birth to ten: child health in South Africa in the 1990s. Rationale and methods of a birth cohort study. Paediatr Perinat Epidemiol. 1991;5(2):211-33. doi.org/10.1111/j.1365-3016.1991.tb00702.x.

17. Richter LM, Norris SA, De Wet T. Transition from Birth to Ten to Birth to Twenty: the South African cohort reaches 13 years of age. Paediatr Perinat Epidemiol. 2004;18(4):290-301. doi.org/10.1111/j.1365-3016.2004.00572.x.

18. Norris SA, Richter LM, Fleetwood SA. Panel studies in developing countries: case analysis of sample attrition over the past 16 years within the birth to twenty cohort in Johannesburg, South Africa. Journal of International Development: The Journal of the Development Studies Association. 2007;19(8):1143-50. doi.org/10.1002/jid.1390.

19. Todd AC, McNeill FE. In vivo measurements of lead in bone using a $109 \mathrm{Cd}$ 'spot'source. Human Body Composition: Springer; 1993. p. 299-302. doi.org/10.1007/978-1-4899-1268-8_66.

20. Gerhardsson L, Attewell R, Chettle D, Englyst V, Lundström N, Nordberg G, et al. In vivo measurements of lead in bone in long-term exposed lead smelter workers. Archives of Environmental Health: An International Journal. 1993;48(3):147-56. doi.org/10.1080/00039896.1993.9940813.

21. Todd AC, McNeill FE, Palethorpe JE, Peach DE, Chettle DR, Tobin MJ, et al. In vivo X-ray fluorescence of lead in bone using K X-ray excitation with $109 \mathrm{Cd}$ sources: radiation dosimetry studies. Environmental research. 1992;57(2):117-32. doi.org/10.1016/S0013-9351(05)80073-8.

22. Todd AC. Coherent scattering and matrix correction in bone-lead measurements. Physics in Medicine \& Biology. 2000;45(7):1953. https://iopscience.iop.org/article/10.1088/0031-9155/45/7/318/pdf. Accessed 18 August 2021.

23. Buss AH, Perry M. The aggression questionnaire. J Personal Soc Psychol. 1992;63(3):452. 
24. Reyna C, Sanchez A, Ivacevich MGL, Brussino S. The Buss-Perry Aggression Questionnaire: construct validity and gender invarianceamong Argentinean adolescents. International Journal of Psychological Research. 2011;4(2):30-7. doi.org/10.21500/20112084.775.

25. Madran P. The reliability and validity of the Buss-Perry Aggression Questionnaire (BAQ)-Turkish version. Turk Psikiyatri Dergisi. 2013;24(2):124.

26. Park SK, Mukherjee B, Xia X, Sparrow D, Weisskopf MG, Nie H, et al. Bone lead level prediction models and their application to examining the relationship of lead exposure and hypertension in the third national health and nutrition examination survey (nhanes-iii). Journal of occupational environmental medicine/American College of Occupational Environmental Medicine. 2009;51(12):1422. doi:10.1097/JOM.0b013e3181bf6c8d.

27. Jebena MG, Lindstrom D, Belachew T, Hadley C, Lachat C, Verstraeten R, et al. Food insecurity and common mental disorders among Ethiopian youth: structural equation modeling. PloS one. 2016;11(11). doi.org/10.1371/journal.pone.0165931.

28. Kosnett MJ, Becker CE, Osterloh JD, Kelly TJ, Pasta DJ. Factors influencing bone lead concentration in a suburban community assessed by noninvasive K x-ray fluorescence. Jama. 1994;271(3):197203. doi:10.1001/jama.1994.03510270043037.

29. Roy M, Gordon C, Beaumont L, Chettle D, Webber C. Further experience with bone lead content measurements in residents of southern Ontario. Applied radiation isotopes. 1997;48(3):391-6. doi.org/10.1016/S0969-8043(96)00223-0.

30. Mathee A, Rollin H, Ditlopo N, Theodorou P. Childhood lead exposure in South Africa. South African Medical Journal. 2008;93(5):313. http://www.samj.org.za/index.php/samj/article/viewFile/2216/1485. Accessed 18 August 2021.

31. Johnston LD, O'Malley PM, Bachman JG, Schulenberg JE, Miech RA. Monitoring the Future national survey results on drug use, 1975-2014: Volume II, college students and adults ages 19-55. Ann Arbor: Institute for Social Research, University of Michigan; 2015.

32. Archer J. Sex differences in aggression in real-world settings: A meta-analytic review. Review of general Psychology. 2004;8(4):291-322. doi.org/10.1037/1089-2680.8.4.291.

33. Tsorbatzoudis H, Travlos AK, Rodafinos A. Gender and age differences in self-reported aggression of high school students. J interpers Violence. 2013;28(8):1709-25. doi.org/10.1177/0886260512468323.

34. Hendricks L, Bore S, Aslinia D, Morriss G, editors. The effects of anger on the brain and body. National forum journal of counseling and addiction; 2013.

35. Hu H, Payton M, Kornc S, Aro A, Sparrow D, Weiss ST, et al. Determinants of bone and blood lead levels among community-exposed middle-aged to elderly men: the Normative Aging Study. Am J Epidemiol. 1996;144(8):749-59. doi.org/10.1093/oxfordjournals.aje.a008999.

36. Dubow EF, Boxer P, Huesmann LR. Long-term effects of parents' education on children's educational and occupational success: Mediation by family interactions, child aggression, and teenage 
aspirations. Merrill-Palmer quarterly (Wayne State University Press). 2009;55(3):p. 224. doi:10.1353/mpq.0.0030.

37. Graber LK, Asher D, Anandaraja N, Bopp RF, Merrill K, Cullen MR, et al. Childhood lead exposure after the phaseout of leaded gasoline: an ecological study of school-age children in Kampala. Uganda Environmental health perspectives. 2010;118(6):884-9. doi.org/10.1289/ehp.0901768.

38. Sargent JD. The role of nutrition in the prevention of lead poisoning in children. Pediatr Ann. 1994;23(11):636-42. doi.org/10.3928/0090-4481-19941101-12.

39. Feigenbaum JJ, Muller C. Lead exposure and violent crime in the early twentieth century. Explorations in economic history. 2016;62:51-86. doi.org/10.1016/j.eeh.2016.03.002.

40. Wright JP, Dietrich KN, Ris MD, Hornung RW, Wessel SD, Lanphear BP, et al. Association of prenatal and childhood blood lead concentrations with criminal arrests in early adulthood. PLoS Med. 2008;5(5). doi.org/10.1371/journal.pmed.0050101.

\section{Figures}

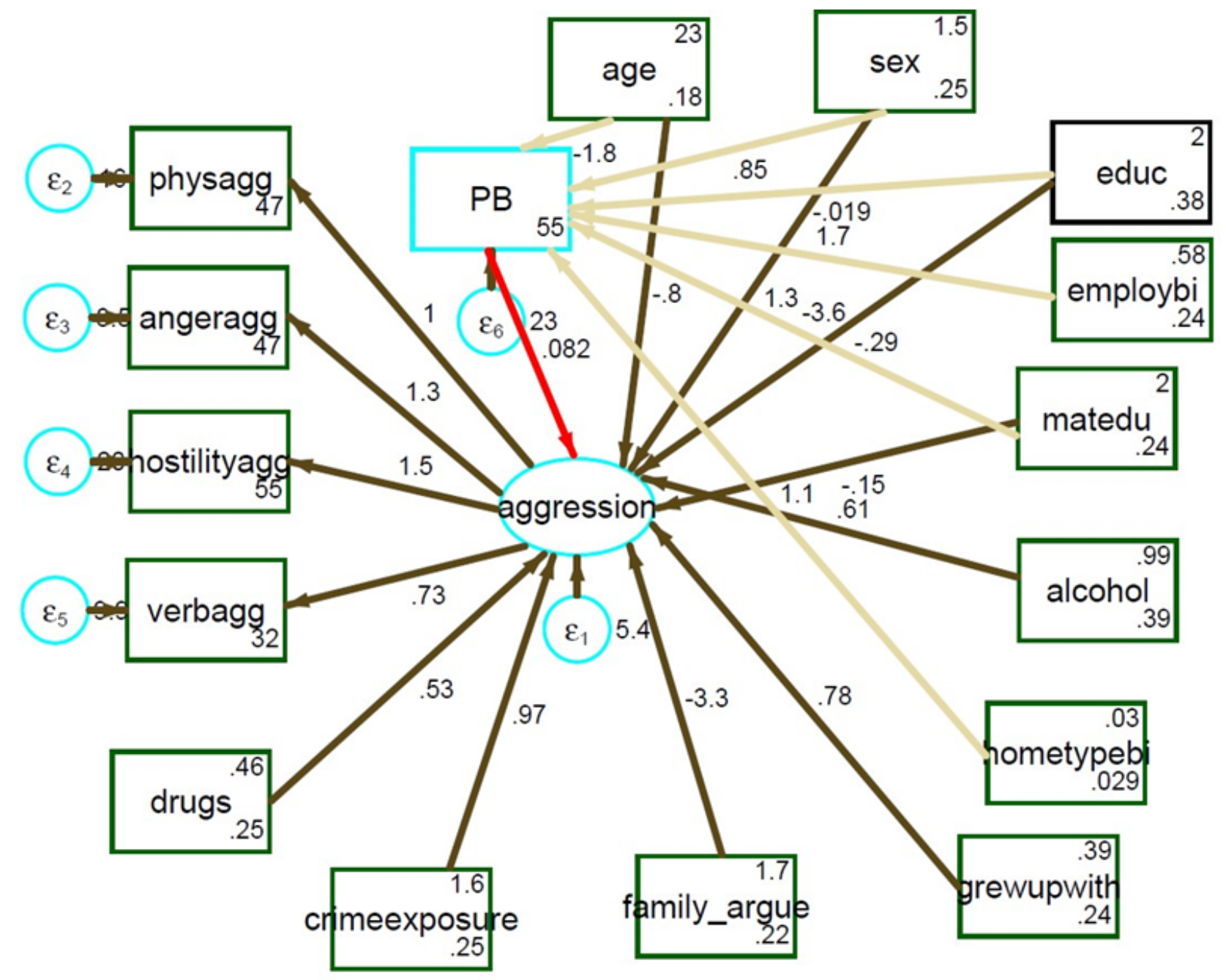

Figure 1 
Path Analysis Between PB, Aggression and Study Predictors. (fit statistics: $\chi 2$ (model vs saturated) $=48.403$ (0.337); RMSE=0.028 (pclose 0.736); CFI=0.970; TLI=0.957; SRMR=0.048 and coefficient of determination=0.43) (matedu=maternal education; hometypei=type of housing; family argue= exposure to family violence; crimeexposure=crime and violence in neighbourhood; employbi=occupational status).

\section{Supplementary Files}

This is a list of supplementary files associated with this preprint. Click to download.

- AdditionalfilesSupplementaryTables14.docx 